\title{
Erratum to: Michael Graf, Dietrich Grönemeyer, Grill, Hans-Dieter Wedig (eds): Beschleunigungsverletzung der Halswirbelsäule: HWS-Schleudertrauma
}

\author{
Springer Verlag, Heidelberg, 2009, XXII, 496 pp, 43 Figures, EURO (D) 99.95, \\ EURO $\left(\mathrm{A}^{\circ}\right)$ 102.75 CHF 155.50 Hardcover, ISBN: 978-3-7985-1837-7
}

\section{Pierre Kehr}

Published online: 6 June 2010

(C) Springer-Verlag 2010

\section{Erratum to: Eur J Orthop Surg Traumatol DOI 10.1007/s00590-010-0604-x}

The analyses in this published book contain errors. Please find below the corrected text:

This 472-page textbook written in German by 84 contributors is a compact review of the actual knowledge in research, diagnosis, therapy and legal aspects of whiplash injury. Experts in biomechanics, medical and dental doctors, therapists and lawyers have contributed to this innovative multidisciplinary work.

The first part includes contributions about basic research, clinical and radiological diagnostic evaluation, therapeutical strategies, including special and rare problems, psychological and psychosomatic aspects.

The relevant anatomical, physiological and neurobiological details as base for a better explanation of the symptoms of this complex disease are summarized. As no morphological changes can be found using the current diagnostic technology in many cases, there is hope coming from basic neuroscience researchers that most of the symptoms can be explained in a near future by understanding the extremely complex neuronal network within the kinematic chain in the cervical spine.

Concussion or contusion of the spinal cord and nerve roots, a CSF leak with intracranial hypotension, subdural

The online version of the original article can be found under doi:10.1007/s00590-010-0604-x.

P. Kehr $(\bowtie)$

SOTEST, Strasbourg, France

e-mail: kehrpier@aol.com hygromas or effusions and disturbances of the CSF circulation may be a consequence of an indirect pressure wave mechanism from the CSF following a direct trauma.

Biomechanical contributions try to give an input for optimizing safety and protection tools within cars.

Further chapters explain why a highly focussed clinical—including neuro-otological—and radiological diagnostic approach (conventional X-Rays, CT, MRI, f-MRI, PET) is warranted in the first post-traumatic examination and in the course of the disease. Upright-MRI as latest technology is, however, not mentioned.

The chapter about therapeutic options focuses on treatments with proven effectiveness, as infiltrations of the facet joints and percutaneous radiofrequency neurotomy.

The problem of functional cranio-cervico-mandibular disturbances is discussed by dentists and orthodentists.

Further contributions are dedicated to neurofeedback, physiotherapy, chiropractic manipulations and osteopathy, but also to "alternative medicine" as acupuncture, homeopathy, meditation, neural, atlas, and cranio-sacral therapies.

Other chapters discuss the psychological, psychiatric and psychosomatic aspects, which are very important for all involved professions. Main topics are post-traumatic stress, neurostress fragmentation, neuropsychological dysfunctions and sleep disorders following a whiplash injury.

The second part is dedicated to the legal aspects of whiplash injuries.

The changes in decisional law in Germany are described, mainly in cases with low-speed car crashes, where the "limits of harmlessness" are discussed.

Apart from the speed at the time of the accident, other factors should and are beginning to be considered: preexisting degenerative spine disease and head "out of position"; finally subsequent post-traumatic psychological problems. 
Other contributions are dedicated to changes in case law in Switzerland and Austria.

In the last chapter the problems associated with health insurance litigations are discussed, including the role of the medical expert as mediator between patients and lawyers.

The EEVC-European Enhanced Vehicle-safety Committee-has presented in October 2005 an "Updated Stateof-the-Art Review on Whiplash Injury Prevention". Reviewed were the "hard facts", including delta-V (change of velocity), head support, head in or "out of position", pre-existing degenerative disease of the cervical spine, type of car, physical analysis of the accident and other factors.
In summary, this book offers excellent multidisciplinary contributions around the complex problem of patients with a whiplash injury.

It is a step towards an optimized diagnostic and therapeutic approach and towards an improved understanding and constructive communication between medical doctors, lawyers and insurance companies.

Although some national guidelines exist already, there is still a long way to go for obtaining generally accepted international guidelines for the management of the whiplash injured patient.

Marugg RA, Kaech DL

Chur (Switzerland)

No funds were received in support of this study. 